\title{
Postmortem audit in a paediatric cardiology unit
}

\author{
G A RUSSELL, P J BERRY
}

From the Department of Paediatric Pathology, Bristol Royal Hospital for Sick Children

SUMMARY Postmortem examinations performed on 76 children with a clinical diagnosis of congenital heart disease were reviewed retrospectively and compared with the findings before death. Both operated and unoperated cases were studied over a three year period. Despite intensive investigation during life, there was a high rate of unsuspected abnormalities at necropsy (80\%): 29 cases had undiagnosed additional cardiac anomalies or surgical flaws, which contributed to death in 13 cases. Defects in surgery were uncommon but permitted modification in surgical technique to avoid recurrence. Myocardial necrosis and pulmonary foreign body embolism were common findings, the importance of which is uncertain and requires further study for their prevention.

Even in the most thoroughly investigated cases postmortem examination has a high yield of clinically important pathology which is undetected during life.

The lamentable decline in the number of necropsies performed in the United Kingdom has been the subject of much comment and speculation. The reasons underlying this change in clinical practice are complex and varied. Many studies by pathologists have shown the continued value of necropsies in clinical audit.' We chose to study a group of children with a very specific diagnostic problem by performing a retrospective review of 76 necropsies performed on children with a clinical diagnosis of congenital heart disease. One of our aims was to assess the claim that modern diagnostic techniques are sufficiently accurate as to negate the value of necropsy. ${ }^{2}$ The children had been thoroughly investigated in life by both invasive and non-invasive imaging. Our experience has allowed us to propose a protocol for this type of examination when performed at specialist centres.

\section{Material and methods}

Seventy six cases from the Bristol paediatric cardiology unit had necropsies performed by the paediatric pathology department during a three year period, 1985-1987. All these children had a clinical diagnosis of congenital heart disease and were under the care of the cardiology and surgical teams; we also included cases who had received cardiological assessment under the care of neonatologists. We did not include cases of cardiological malformation diagnosed antenatally and aborted as these seemed to form a distinct group with different diagnostic problems.

Case notes were examined and the findings from

Accepted for publication 20 April 1989 clinical observations, echocardiography, and angiography recorded. Details of surgical intervention and other treatment were noted. A synopsis of the final clinical diagnosis was made. The necropsy report was then reviewed and the findings summarised and compared with the clinical assessment. When available the heart was re-examined to resolve any points that were unclear from the report. No major modifications, however, were made to the necropsy accounts of the cardiac abnormalities. The original histological preparations from each case were reviewed and the findings recorded without knowledge of the original report. Cases were then categorised into four main groups:

Group: $A$ where the necropsy showed additional undiagnosed cardiac lesions;

Group B: where the necropsy showed unsuspected major or minor complications of cardiac disease or of its treatment;

Group C: where the necropsy showed additional clinically important pathology not directly resulting from the cardiac condition;

Group D: where the necropsy yielded no additional information.

Groups A, B, and C were not mutually exclusive; group D formed a completely separate category.

\section{Results}

Seventy six consecutive cases from the Bristol paediatric cardiology and cardiac surgery departments were reviewed. The sex ratio was exactly equal with 38 boys and 38 girls. Forty eight $(63 \%)$ of the necropsies were performed for Her Majesty's Coroner, 
Bristol. The usual reason for referral to the Coroner was that recent surgery had been performed. Twenty two children had died within 24 hours of their operation. The methods used by the pathologist were the same for both types of case. Sixty nine of the postmortem examinations were performed by the two authors, the rest were done by other members of the pathology department under supervision. The age range of cases was between a few hours and 11 years: $<24$ hours $(\mathrm{n}=3)(4 \%) ; 24$ hours-7 days $(\mathrm{n}=12)$ $(16 \%) ; 7$ days-1 month $(\mathrm{n}=7)(9 \%)$; 1 month-1 year $(n=28)(37 \%)$; > 1 year $(n=26)(34 \%)$.

All the children had echocardiographic imaging of the heart and multiple examinations had often been made. In 16 cases echocardiography had been the only mode of examination; this was often because invasive catheterisation was contraindicated due to the child's poor clinical condition. Sixty cases had had both cardiac catheterisation and echocardiography. Cardiac surgery had been performed on 60 children, 37 on cardiopulmonary bypass. Sixteen children had died within 24 hours of open heart surgery and six within the same time following closed operations.

\section{GROUP A}

Twenty nine $(38 \%)$ cases had additional cardiac lesions found at necropsy. These were subdivided into four subgroups to reflect the implications of the extra lesions found:

subgroup I where the cardiac diagnosis before death was completely wrong.

subgroup II where the diagnosis before death was only partly correct and additional lesions were missed that might have influenced the management.

subgroup III cases where cardiac surgery was imperfect or inappropriate to the lesion found.

subgroup IV cases where the cardiac diagnosis before death was substantially correct but additional lesions were found at necropsy that would not have affected the management had they been diagnosed in life.

Four cases appeared in more than one subgroup but these were counted only once in the total of 29 cases.

Only one case appeared in subgroup I. This was a child who died at 4 hours of age in heart failure. A clinical diagnosis of Ebstein's anomaly of the tricuspid valve was based on a single echocardiographic examination. Postmortem examination showed a fistula between the left coronary artery and the coronary sinus; the tricuspid valve was normal. The child also had severely hypoplastic lungs.

Subgroup II contained seven $(\mathbf{9 \%})$ cases where important cardiac anomalies had been missed (table 1). These included a range of anomalies in the setting
Table 1 Missed cardiac lesions that would have influenced management had they been detected

\begin{tabular}{|c|c|}
\hline Additional necropsy finding & Clinical diagnoses confirmed \\
\hline \multirow{7}{*}{$\begin{array}{l}\text { Aortopulmonary window } \\
\text { Unilateral partial anomalous } \\
\text { pulmonary venous drainage } \\
\text { Atrioventricular septal defect and } \\
\text { cleft mitral valve cusp } \\
\text { Closed secundum ASD } \\
\text { + patent Blalock shunt } \\
\text { (closed on echocardiogram) } \\
\text { Mitral valve dysplasia } \\
\text { Secundum ASD } \\
\text { (misinterpreted as dilated } \\
\text { coronary sinus) }\end{array}$} & Interrupted aortic arch \\
\hline & Ventricular septal defect \\
\hline & $\begin{array}{l}\text { Transposition of great } \\
\text { vessels }\end{array}$ \\
\hline & $\begin{array}{l}\text { Pulmonary atresia, mitral } \\
\text { atresia, univentricular } \\
\text { heart }\end{array}$ \\
\hline & Aortic stenosis \\
\hline & Fallot's tetralogy \\
\hline & Interrupted aortic arch \\
\hline
\end{tabular}

ASD = atrial septal defect; VSD = ventricular septal defect.

of other complex cardiac lesions. Aortopulmonary window was missed twice in children with interrupted aortic arches. In four of these seven cases diagnosis had been based solely on echocardiography.

In seven cases surgical flaws were found at necropsy (subgroup III, table 2). In five of these the surgical problem was probably a contributing factor in the patient's death; the flaws were of more doubtful clinical importance in the other cases.

The largest number of cases were in subgroup IV ( 18 cases, $24 \%$ ). This included many minor cardiac abnormalities such as small muscular ventricular septal defects. We included some major abnormalities if they were present in the setting of other correctly diagnosed severe malformations and where the diagnosis of the missed anomaly would not have affected outcome. The cases are listed in table 3.

\section{GROUP B}

Undiagnosed complications of the congenital heart disease or of its treatment were common at necropsy (51 cases, 67\%) (table 4). The most common undiagnosed abnormality was myocardial necrosis, present in $30(40 \%)$ cases. Typically this affected the subendocardial portion of the left ventricular myocardium,

Table 2 Surgical imperfections detected at necropsy

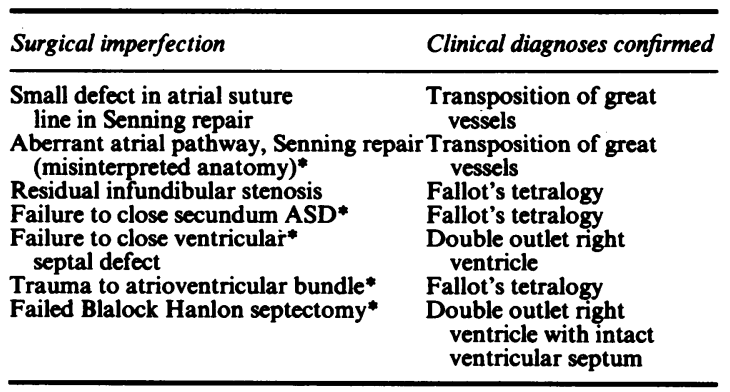

*Cases where surgical flaw probably contributed to death. 
the mitral papillary muscles being particularly vulnerable. Twenty six of these $\mathbf{3 0}$ died following recent cardiac surgery, 12 within 24 hours of operation; 19 of the 26 had had open heart surgery.

Myocardial necrosis had more varied appearances than in adults. Occasionally the areas of necrosis were visible as dusky irregular subendocardial patches. Less commonly these patches were visible as green stained areas in jaundiced children (fig 1), or creamy yellow speckled areas when extensively calcified (fig 2). In most cases, however, necrosis was only apparent on histological examination. When children had died within 24 hours of operation, zones of eosinophilic necrosis, cytoplasmic coagulation, and loss of nuclear staining were seen. Calcification was common and often extensive (fig 3). It was sometimes present in children in whom the duration of myocardial necrosis was presumed to have been short (those dying within 24 hours of operation), suggesting a very rapid onset. Older lesions showed fibrosis and calcification, inflammation was uncommon. The size of necrotic areas varied from small islands around the lumen of the left ventricle to confluent geographical zones

Table 3 Additional undiagnosed anomalies of less importance

\begin{tabular}{|c|c|}
\hline Additional necropsy finding & Clinical diagnoses confirmed \\
\hline Secundum ASD & Patent ductus arteriosus \\
\hline $\begin{array}{l}\text { Hypoplastic tricuspid valve } \\
\text { (atretic on echocardiogram) }\end{array}$ & $\begin{array}{l}\text { Pulmonary atresia with } \\
\text { intact ventricular septum }\end{array}$ \\
\hline $\begin{array}{l}\text { Left atrial isomerism, aortic } \\
\text { atresia, hypoplastic mitral } \\
\text { valve (atretic on scan) }\end{array}$ & Hypoplastic left ventricle \\
\hline $\begin{array}{l}\text { Left superior vena cava } \\
\text { draining into coronary sinus }\end{array}$ & Fallot's tetralogy \\
\hline Right atrial isomerism & $\begin{array}{l}\text { Mitral atresia, } \\
\text { univentricular heart }\end{array}$ \\
\hline Right sided aortic arch & Truncus arteriosus \\
\hline $\begin{array}{l}\text { Double inlet left ventricle } \\
\text { (tricuspid valve thought to } \\
\text { be atretic) }\end{array}$ & $\begin{array}{l}\text { Transposition of great } \\
\text { vessels univentricular } \\
\text { heart }\end{array}$ \\
\hline $\begin{array}{l}\text { Left ventricular myxoma, } \\
\text { abnormal mitral valve insertion } \\
\text { left atrial isomerism }\end{array}$ & $\begin{array}{l}\text { Right atrial myxoma, } \\
\text { double chamber right } \\
\text { ventricle atrioventricular } \\
\text { septal defect }\end{array}$ \\
\hline Small perimembranous VSD & $\begin{array}{l}\text { Total anomalous } \\
\text { pulmonary venous } \\
\text { drainage }\end{array}$ \\
\hline $\begin{array}{l}\text { Double orifice mitral valve } \\
\text { bicuspid aortic valve } \\
\text { small muscular VSDs }\end{array}$ & $\begin{array}{l}\text { Atrioventricular septal } \\
\text { defect (complete) }\end{array}$ \\
\hline Aneurysm of fossa ovalis & Muscular VSDs \\
\hline Double orifice mitral valve & $\begin{array}{l}\text { Atrioventricular septal } \\
\text { defect (complete) }\end{array}$ \\
\hline Aortic atresia & Aortic stenosis \\
\hline $\begin{array}{l}\text { Complete atrioventricular septal } \\
\text { defect }+ \text { failed to } \\
\text { confirm aortopulmonary window }\end{array}$ & Pulmonary stenosis \\
\hline Small muscular VSDs & $\begin{array}{l}\text { Transposition of great } \\
\text { vessels }\end{array}$ \\
\hline $\begin{array}{l}\text { Hypoplastic mitral valve } \\
\text { (interpreted as mitral atresia) }\end{array}$ & $\begin{array}{l}\text { Hypoplastic left ventricle, } \\
\text { double outlet right } \\
\text { ventricle intact } \\
\text { ventricular septum }\end{array}$ \\
\hline Small perimembranous VSD & Interrupted aortic arch \\
\hline
\end{tabular}

Table 4 Group B: where necropsy showed minor or major complications of congenital heart disease or of its treatment

Myocardial necrosis 30

Foreign body emboli

Pulmonary emboli

Cerebral infarction and necrosis

Small intestinal necrosis

Pulmonary hypertension

Birth asphyxia

Renal infarction

Splenic infarction

Haemopericardium (resuscitation injury)

Haemothorax

Superior vena cava obstruction

Duodenal ulcers

Renal vein thrombosis

Acute pancreatitis

Adrenal infarction

Aspergillus endocarditis

Systemic aspergillosis

Cytomegalovirus inclusions in lung and kidney

Adenovirus type II cultured from lung

Streptococcus pneumoniae septicaemia

Haemophilus influenzae pericarditis

extending transmurally or affecting the right ventricle or atria.

We were surprised at the prevalence of foreign body embolism in this series. Nineteen children had fragments of foreign material within small arteries of their lungs. In only one case were foreign bodies found in organs other than the lungs. At least three differento materials could be distinguished by their light

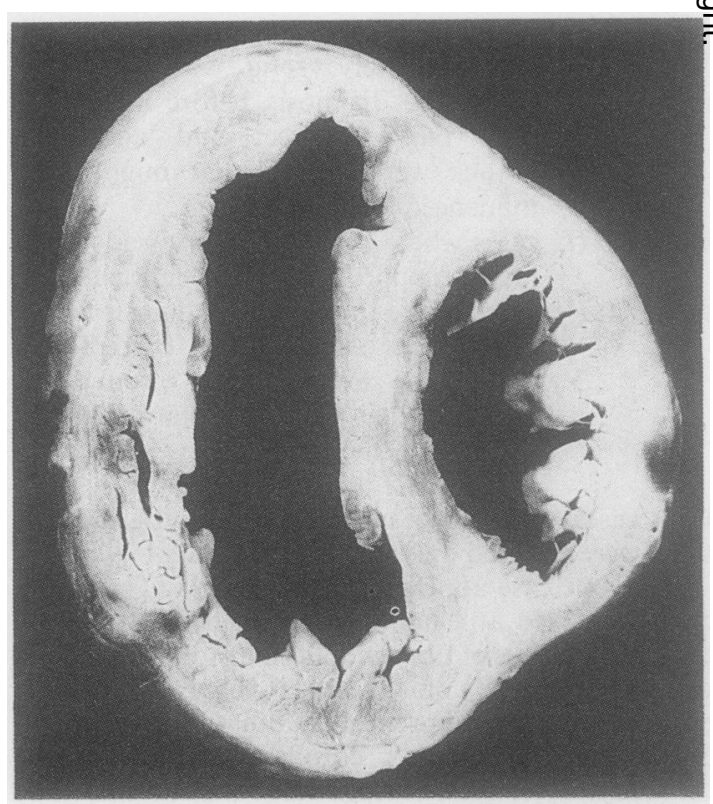

Fig 1 Green stained areas of myocardial necrosis from a child of 8 months of age who became jaundiced and died six days after surgery for repair of an atrioventricular septal defect. 


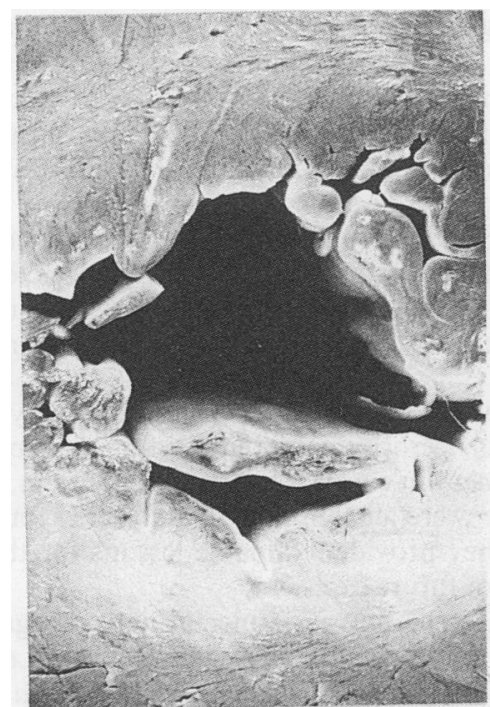

Fig 2 Calcified subendocardial necrosis in a 12 week old child with severe aortic valve stenosis.

microscopic appearance. The fragments were often surrounded by multinucleated foreign body giant cells. Changes in the adjacent blood vessel wall were rare, an exception being one child who died three months after repair of transposition of the great vessels (fig 4). The source of embolism in these 19 children was uncertain; 18 children had had previous cardiac surgery, 11 on cardiopulmonary bypass. Sixteen cases had had invasive cardiac angiography, another possible source.

Unsuspected pulmonary thromboemboli were observed in six cases. Cerebral infarcts and peri-

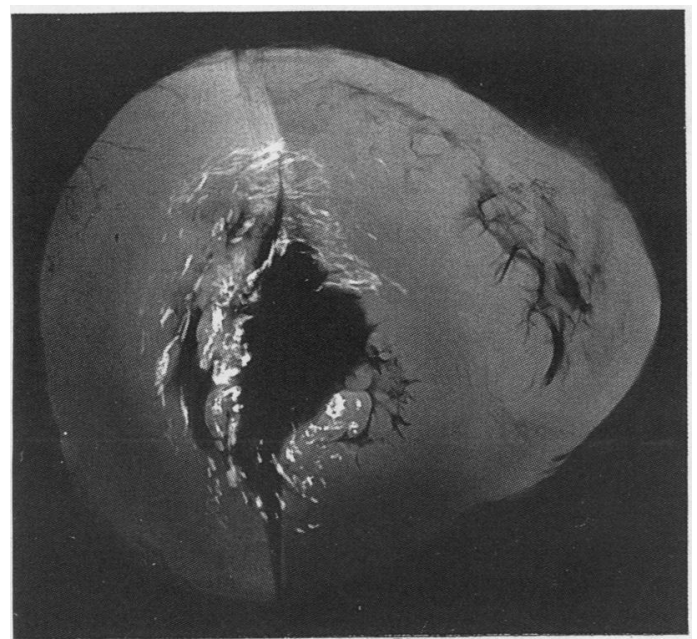

Fig 3 Radiographic demonstration of extensive subendocardial calcification from the same case shown in fig 2.

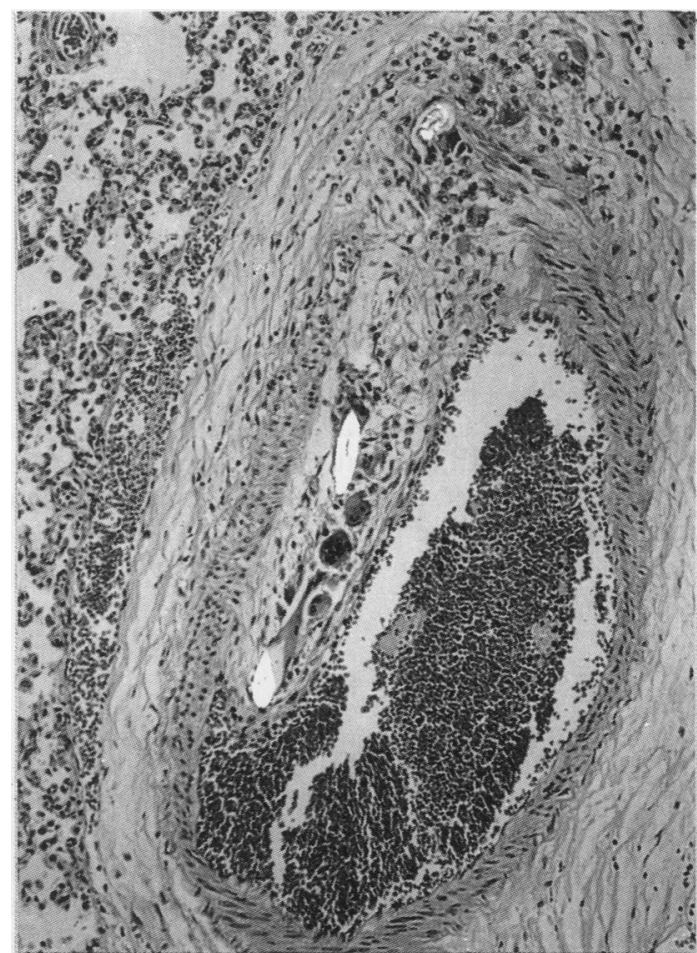

Fig 4 Foreign body microemboli exciting a destructive giant cell reaction in a pulmonary artery of a 14 month old child who died eight weeks after repair of a complete transposition. (Haematoxylin and eosin.)

ventricular leucomalacia were found in a further five children. Changes of pulmonary hypertension were rarely seen as an unexpected finding at necropsy, as it was frequently correctly diagnosed in life. Three cases of pulmonary hypertension of an unexpected severity were found. In only one of these were the changes within the irreversible grades of the Heath Edward's classification. For simplicity we chose to include infective complications in group B, even though it was sometimes unclear whether these were a result of the heart disease or incidental. Six children had unsuspected infections which probably caused death in four cases.

Changes of adult respiratory distress syndrome ('shock lung') (11 cases) and hepatic pathology (five cases of midzonal necrosis and five cases of severe hepatic fibrosis) were not included in group B. This was because these conditions were clinically manifest and were being investigated and treated, even though the underlying pathology was not always appreciated clinically.

GROUPS C AND D

The cases in group $\mathrm{C}$ (incidental pathology) are listed 
Table 5 Group C: where necropsy showed clinically important extracardiac pathology

Polysplenia

Cerebral arteriovenous malformation

Pulmonary hypoplasia

di George's syndrome

Hepatoblastoma

Asplenia

Pulmonary haemangiomata

Abnormal karyotype

Lymphocytic thyroiditis

in table 5. In only one case was the extracardiac pathology the cause of death (cerebral arteriovenous malformation with associated infarction). The other anomalies, however, sometimes helped in the attribution of a "syndrome" to the case. In 15 cases no additional information was obtained by necropsy (group D).

\section{Discussion}

The claim that necropsy has been rendered obsolete by the improved techniques of modern clinical diagnosis is refuted by this study. Admittedly, in only one of our cases did postmortem examination show clinical cardiac diagnosis to be completely wrong. The criteria for assessing the value of necropsy, however, must be broader than merely the complete disagreement of clinical and necropsy diagnosis. In our series $38 \%$ of cases had undiagnosed additional cardiac anomalies or surgical flaws which may have contributed to death in 13 cases. Porter and Keeling's study found a high rate of significant discrepancy between necropsy and clinical diagnoses. ${ }^{3}$ Forty four percent of postmortem examinations on neonatal deaths in that series yielded clinically important information. In our series of more highly investigated children $80 \%$ of necropsies yielded additional information, although the precise clinical importance of some of the findings has yet to be evaluated. Intensive clinical investigation in life increases the need for detailed post mortem examination to ensure that the basis for the adopted treatment was sound.

A disproportionate number of the major clinicopathological discrepancies arose in children who had only had echocardiographic assessment (four out of seven cases). This supports the observation of Goldman, ${ }^{4}$ who found that discrepancies at necropsy were much more common in cases where diagnosis was based solely on the result of a newer technique such as ultrasound, computed tomography scanning, or nuclear medicine than those based on other investigations. In our study aortopulmonary window caused particular diagnostic problems on echocardiography as this region is hard to visualise. It was missed twice in children with interrupted aortic arch, a well recognised though rare association and diagnostic pitfall. $^{5}$ Aortopulmonary window was also erroneously diagnosed in a child with a complete atrioventriculoseptal defect. Minor unsuspected cardiac lesions were found in $28 \%$, illustrating the incomplete resolution of these forms of cardiac imaging. These lesions would not have influenced the management or outcome had they been detected. They may assume greater importance, however, as methods of treating the severe concomitant abnormalities improve.

Scrutiny of highly skilled, complex surgery on tiny hearts at necropsy is essential for the continued improvement in surgical technique. Flaws in surgical technique were uncommon in our series but when present they provided valuable lessons for the management of future cases.

Myocardial necrosis is increasingly recognised in children dying in the perinatal period. Less well recognised is the association of necrosis with cardiac malformation when the distribution of dead tissue may reflect the site of an obstructive cardiac lesion. ${ }^{6}$ The necroses in our cases were presumed to be related to recent cardiac surgery in most cases. Techniques of paediatric myocardial preservation during bypass operations are less well determined than for adult procedures.

It is difficult to be certain of the clinical importance of the foreign body embolism in the lungs of these cases. The ease of their histological demonstration, on random lung sections, suggest that they were present in large numbers. Filter material, plastic tubing, and antifoaming agents are well documented sources of embolism following cardiac bypass procedures but these usually have systemic distribution. ${ }^{7}$ Other sources also have to be excluded as not all the cases occurred following surgery. Although we have no evidence that these emboli caused problems in the children, the long term consequences may be important in these patients who often already have impaired pulmonary circulation.

Both these complications of myocardial necrosis and foreign body embolism were shown by histological examination. This highlights the essential role of routine histological sampling even in the absence of macroscopic lesions.

Clinically important incidental abnormalities were uncommon but when present sometimes led to a unifying diagnosis for the case. No additional information was obtained from $20 \%$ of cases. As paediatric pathologists we are aware of the value of negative findings in counselling bereaved parents. Although unsatisfactory in explaining the outcome of the case, the negative findings may still be used to comfort parents that all appropriate measures had been taken.

Pathologists must share some of the blame for the 
Fig 5 Suggested protocol for paediatric cardiac necropsy

Review notes/discuss with clinicians vitreous for urea and sodium skin for karyotype

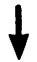

Consider contrast radiology ${ }^{10}$

Document external anomalies scars/drains/pacing wires

\begin{tabular}{|c|c|}
\hline CARDIAC & EXTRACARDIAC \\
\hline $\begin{array}{l}\text { examine in-situ } \\
\text { especially bilateral SVC, } \\
\text { pulmonary veins } \\
\text { cardiac position } \\
\text { suture lines/pacing wires } \\
\text { phrenic nerves } \\
\text { IVC continuity } \\
\text { azygous veins } \\
\text { aortic arch/coronaries } \\
\text { collaterals } \\
\text { formalin perfusion or } \\
\text { inflation }{ }^{11} \text { dissection: } \\
\text { traditional } \\
\text { or windows } \\
\text { or echo planes } \\
\text { photograph } \\
\text { draw anomalies } \\
\text { histology: all chambers } \\
\text { conducting system } \\
\text { wax impregnate specimen }\end{array}$ & $\begin{array}{l}\text { lung for culture } \\
\text { search for emboli } \\
\text { infarcts } \\
\text { anatomical anomalies } \\
\text { situs } \\
\text { spleen(s) } \\
\text { lung markings } \\
\text { bronchi } \\
\text { fix brain and cord } \\
\text { inflate lungs } \\
\text { histology: all viscera } \\
\text { lung lobes } \\
\text { brain } \\
\text { liver } \\
\text { kidneys } \\
\text { adrenals } \\
\text { thromboemboli }\end{array}$ \\
\hline
\end{tabular}

formalin perfusion or

inflation" dissection:

traditional

or windows

or echo planes

draw anomalies

histology: all chambers

wax impregnate specimen ${ }^{9}$

ISSUE REPORT PROMPTLY

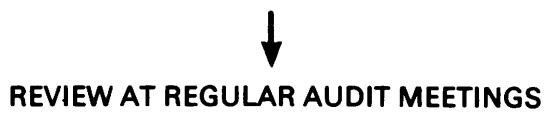

Fig 5 A protocol for cardiac necropsy.

decline in necropsy rate in this country through their lack of advocacy and their unwillingness to modify age old practice to suit changing clinical needs. We must monitor the value of our work constantly and publicise it to our clinical colleagues. As well as giving us insights into the mechanisms of death the necropsy may highlight unsuspected problems whose importance is uncertain and which require further study for their prevention. Effective audit of deaths in specialist clinical centres requires a high necropsy rate and a technique adapted to suit the clinical problems posed.

Appendix: a protocol for the cardiac necropsy in children

The basis of the "cardiac necropsy" must be a standard thorough paediatric postmortem examination, of which several excellent accounts may be found. ${ }^{8}$ There is no single correct method for performing the necropsy on the child with congenital heart disease. The optimal method takes into account the clinical diagnoses and investigations done in life and is tailored to the optimal demonstration of the anticipated anomalies. The risk of such an approach is that the pathologist becomes blinkered by natural attention to the cardiovascular system and neglecting the remaining examination.

The protocol outlined in fig 5 is time consuming and as such is probably only appropriate to specialist centres where most of these necropsies are performed. Some of the methods are mutually exclusive-for example, histological examination of the conducting system prevents preparation of a specimen impregnated with wax. ${ }^{9}$ The most appropriate methods must be selected for the individual case.

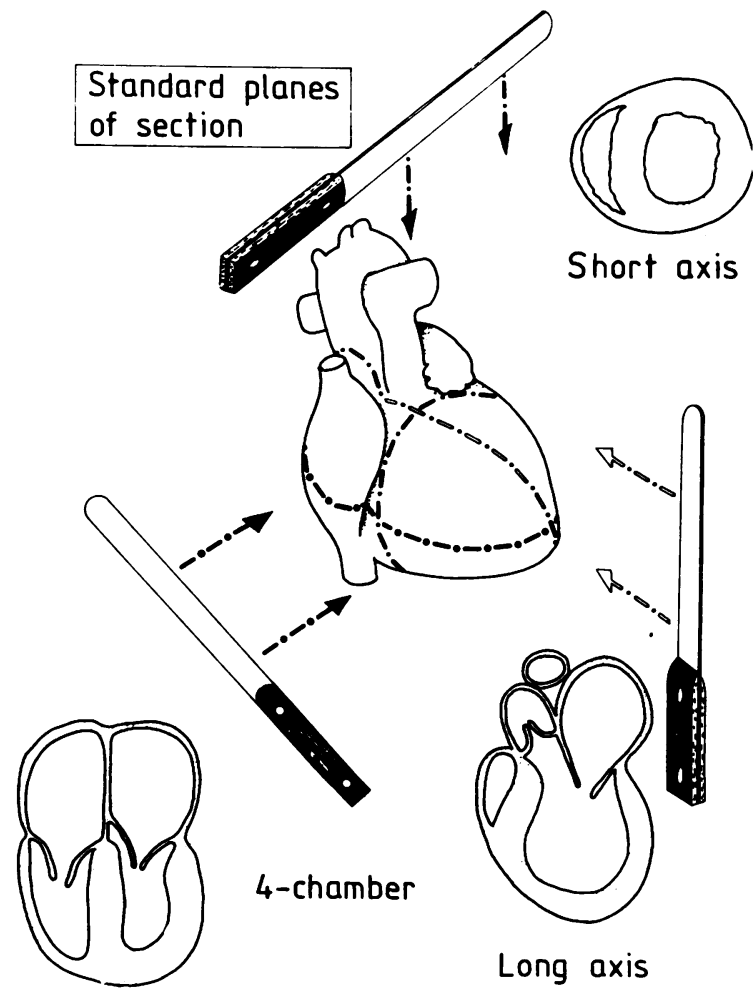

Fig 6 Standard planes of section for comparison with echocardiograms. 


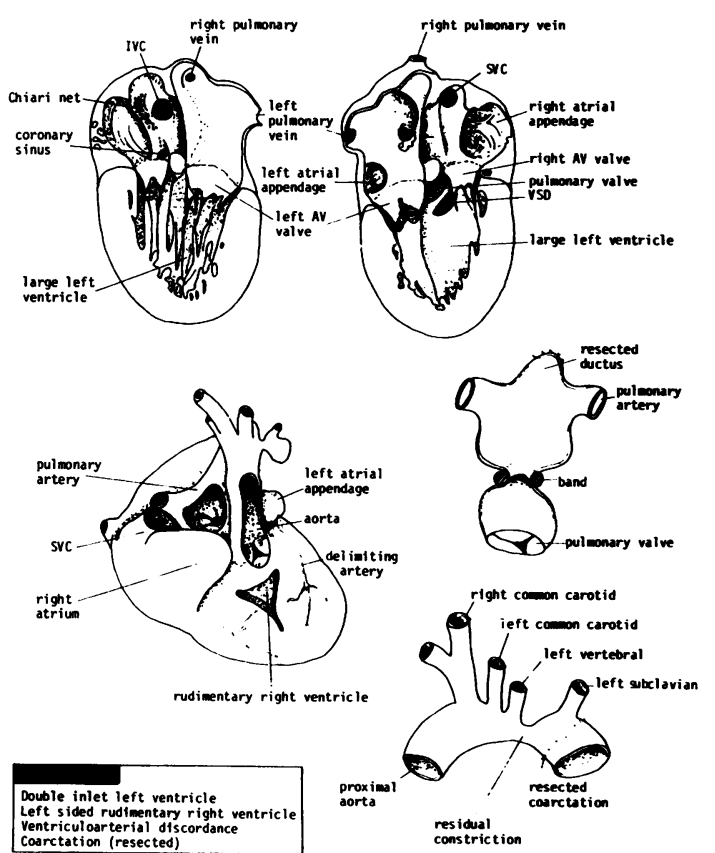

Fig 7 Summary diagram of findings at necropsy issued with the descriptive report.

Much useful information can be obtained before the start of the postmortem examination. Contrast radiology is a simple means of accurately documenting the vascular abnormalities before they are disrupted by dissection and may detect minor anomalies that are easily missed. ${ }^{10}$ Perfusion fixation of the heart ${ }^{11}$ makes dissection much easier and leaves an organ whose anatomy bears more resemblance to the in vivo heart than the residue of the routine cardiac dissection performed at most necropsies. Sectioning along standard planes (fig 6) yields useful correlation with two dimensional echocardiography. More than one plane may be examined by reassembling the heart with "superglue" and resectioning. Photographs of each plane of section should be taken. Cutting windows into the free walls of the chambers leaves a specimen more suited to wax impregnation and subsequent examination at clinicopathological meetings. This method may also be used effectively on postoperative hearts where grafts, shunts, and sutures may confuse interpretation following other dissection techniques. Histological examination of the conducting system is only indicated where surgery has been performed in its proximity or where rhythm disturbances have been shown in life. Simple blocking of the conducting system is performed where gross lesions are sought. Subtle abnormalities require serial sectioning of the entire system. ${ }^{12}$ Even so, the method in children generates far fewer sections than in adults and can give valuable information.

Documentation of cardiac lesions is essential for subsequent clinicopathological discussion. We issue drawings of complex anomalies with the initial report. These rapidly convey the essence of the long report in a more digestible form (fig 7). All hearts are photographed; complex lesions may require multiple views at different stages of dissection. We attend regular review meetings in which cases are discussed by cardiologists, surgeons, radiologists, anaesthetists and pathologists. The aim is to formulate strategies for the prevention of the problems shown at necropsy where these problems are avoidable.

We thank Mr JD Wisheart, consultant cardiac surgeon, for reviewing the manuscript, and our clinical colleagues in the departments of cardiology and cardiac surgery for their support. Mrs Jill Tyley provided invaluable secretarial assistance.

\section{References}

1 McPhee SJ, Bottles K. Autopsy: Moribund art or vital science Am J Med 1985;78:107-13.

2 Anonymous. Autopsy rate [Editorial]. Hum Pathol 1985;16:1179

3 Porter HJ, Keeling JW. Value of perinatal necropsy examination.? J Clin Pathol 1987;40:180-4.

4 Goldman L, Sayson R, Robbins S. Value of autopsy in three medical eras. $N$ Engl J Med 1983;308:1000-5.

5 Fisher EA, Dubrow IW, Eckner FAD, Hastreiter AR. Aorticopulmonary septal defect and interrupted aortic arch: a diagnostic challenge. Am J Cardiol 1974;16:406-26.

6 Franciosi RA, Blanc WA. Myocardial infarcts in infants and children. I. A necropsy study in congenital heart disease. J Paediatr 1968;73:309-19.

7 Orenstein JM, Sato N, Aaron B, Bucholz B, Bloom S. Microemboli observed in deaths following cardiopulmonary bypass surgery. Hum Pathol 1982;13:1082-90.

8 Keeling JW. The perinatal necropsy. In: Keeling JW ed. Fetal and neonatal pathology. London: Springer Verlag, 1987:1-30.

9 Russell GA, Berry PJ. Approaches to the demonstration of congenital heart disease. J Clin Pathol 1986;39:503-7.

10 Russell GA, Berry PJ. Postmortem radiology in children with congenital heart disease. J Clin Pathol 1988;41:830-8.

11 Thomas AC, Davies MJ. The demonstration of cardiac pathology using perfusion-fixation. Histopathology 1985;9:5-19.

12 Anderson RH, Yen Ho S, Smith A, Wilkinson JL. Study of the cardiac conduction system in the paediatric age group. Diagn Histopathol 1981;4:3-15.

Requests for reprints to: Dr G A Russell, Department of Paediatric Pathology, Bristol Maternity Hospital, Southwell Street, Bristol, England. 